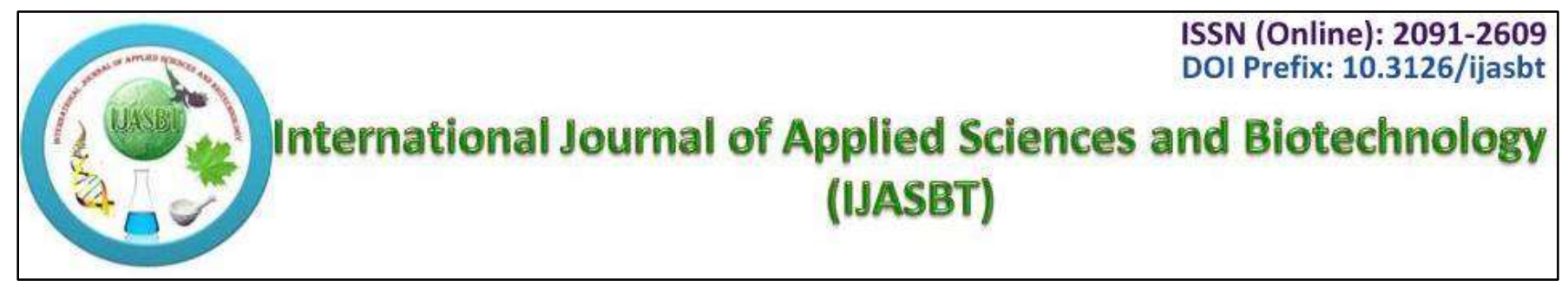

Research Article

\title{
Evaluation of Bermuda grass (Cynodon dactylon (L.) Pers.) and Bahia grass (Paspalum notatum Flugge) for short-term drought tolerance targeting low-maintenance landscaping
}

\author{
C.K. Beneragama ${ }^{1 *}$, G.D. Kapila Kumara ${ }^{2}$ \\ ${ }^{1}$ Department of Crop Science, Faculty of Agriculture, University of Peradeniya, Sri Lanka \\ ${ }^{2}$ Department of Export Agriculture, Faculty of Agricultural Sciences, Sabaragamuwa University of Sri Lanka, \\ Belihuloya, Sri Lanka
}

\begin{abstract}
Drought responses of turf-type Bermuda grass (Cynodon dactylon (L.) Pers.) and Bahia grass (Paspalum notatum Flugge) in relation to their growth, carbon allocation and accumulation of nonstructural carbohydrates were investigated. Seedlings were exposed to a 20 day terminal drought, followed by 20 day recovery with irrigation. Leaf dry matter was lower in water-stressed plants than control plants by the end of drought, but did not differ in roots. For both species, more carbon was allocated towards roots in response to drought. Total nonstructural carbohydrate (TNC) concentration in shoots was increased in drought-stressed plants of both species. However, root TNC concentrations in Bahia grass were decreased after drought. TNC pool sizes also showed a similar variation, hence correlated with TNC concentrations. Bahia grass maintained a better quality than Bermuda grass after the drought, having recorded a higher aesthetic score, higher relative water content and a lower electrolyte leakage. Results suggest that, both species are considerably tolerant to short-term drought though Bahia grass seems more promising.
\end{abstract}

Keywords: Bahiagrass, bermudagrass, carbon allocation, nonstructural carbohydrates

\section{Introduction}

Bermudagrass (Cynodon dactylon (L.) Pers.) and Bahia grass (Paspalum notatum Flugge) are two popular polymorphic turf grass species having $\mathrm{C}_{4}$ photosynthetic pathway. Both species are distributed most abundantly in tropical and subtropical regions, but are sparsely distributed in temperate regions (Galiano, 1985; Tischler and Burson, 1995). These grasses often experience terminal droughts due to which, the reduced performances and quality are the ultimate consequences. It is well established that waterstressed plants tend to have a smaller proportion of their biomass as shoots (i.e. reduced shoot mass ratio - SMR). This ontogenic drift may effectively reduce stress at leaf level, while reducing the whole-plant growth (Fernandez et al., 2002).

\section{Cite this article as:}

C.K. Beneragama, G.D. Kapila Kumara (2018) Int. J. Appl. Sci. Biotechnol. Vol 6(1): 12-16. DOI: 10.3126/ijasbt.v6i1.19304

$1 *$ Corresponding author

C.K. Beneragama,

Department of Crop Science, Faculty of Agriculture, University of Peradeniya, Sri Lanka

Email: chalindab@gmail.com

Peer reviewed under authority of IJASBT

(C) 2018 International Journal of Applied Sciences and Biotechnology 
Nonstructural carbohydrates are the major reserve constituents in plants, comprise of sugars, fructosans and starch. Nevertheless, predominant carbohydrate reserves stored by tropical and subtropical grasses are sucrose and starch (White, 1973). The importance of accumulated carbohydrates in grasses under drought conditions relates both to their role in osmotic adjustment and in supporting regrowth (King et al., 1997). In the short term, carbohydrates accumulate in water-stressed plants because growth is impaired before photosynthesis declines (Deregibus et al., 1982).

Little information is available related to drought induced carbohydrate reserves in $\mathrm{C}_{4}$ grasses, turfgrass used in landscaping in particular. Therefore, the present study was carried out with the objectives of (i) to evaluate the morphophysiological responses of Bermuda grass and Bahia grass to terminal drought (ii) to determine the total nonstructural carbohydrate (TNC) concentrations and pool sizes of two grass species in response to drought, and (iii) to determine if resilience is associated with TNC concentrations or pools.

\section{Materials and Methods}

\section{Plant Establishment and Stress Treatment}

The study was conducted in a growth chamber with temperatures of $25 \pm 2{ }^{\circ} \mathrm{C}$ day $/ 15 \pm 2{ }^{\circ} \mathrm{C}$ night, and a photoperiod of $14 \mathrm{~h}$. Photosynthetically active radiation (PAR) just above the turf canopy at noon, averaged 850 $\mu$ mol. $\mathrm{m}^{-2} \mathrm{~s}^{-1}$ during the study period. Seeds of Bermuda grass and Bahia grass were sown in plastic pots $(15 \mathrm{~cm}-$ diameter, $15 \mathrm{~cm}$-deep) filled with soil (Red Yellow Podsolic: $\mathrm{pH}-6.8$, bulk density - $1.1 \mathrm{~g} . \mathrm{cm}^{-3}$ ). Until the experiment begins (20 days after germination - DAG), plants were watered every 4 days to bring soil to near field capacity. Thereafter, plants were subjected to water-deficit stress by withholding water (terminal drought) or were maintained well-watered (control) for 20 days (40 DAG). Stressed plants were re-watered and maintained wellwatered for another 20 days (60 DAG). Sampling was done on 20,40 and $60^{\text {th }}$ days.

\section{Plant Growth Analysis}

Shoot and root samples were oven dried at $70{ }^{\circ} \mathrm{C}$ for 48 hours to determine the dry mass. These values were used in calculating the shoot mass ratio (SMR; shoot mass/plant mass) and root mass ratio (RMR; root mass/plant mass). Relative growth rate (RGR) was determined using the classical approach, describing the change in natural logtransformed plant mass over time (Hunt, 1982).

\section{Aesthetic Evaluation}

Visual scores for turf quality were assigned to each species across treatments. Turf aesthetics was scored from 1 to 10 , with 10 equaling ideal quality based on shoot density, colour and uniformity.

\section{Relative Water Content}

Leaf water status was determined by measuring relative water content (RWC) of young and fully expanded (YFE) leaves, calculated as follows: RWC $=(F W-D W) /(T W-D W)$ $\times 100$, where, $F W$ is the fresh weight, $D W$ is the dry weight and $T W$ is the turgid weight of leaf tissue after being soaked in water for $5 \mathrm{~h}$ at room temperature (Barrs and Weatherly, 1962).

\section{Electrolyte Leakage}

Electrolyte leakage (EL) was measured using YFE leaves as described in Nayyar and Chander (2004). Leaf pieces were rinsed thrice with deionized water and placed in glass tubes containing $30 \mathrm{ml}$ of deionized water. These tubes were incubated for 24 hours at room temperature and subsequently determined the electrical conductivity of the solution $\left(\mathrm{EC}_{1}\right)$. Same samples were then boiled for 20 minutes followed by measuring the final electrical conductivity $\left(\mathrm{EC}_{2}\right)$. The $\mathrm{EL}$ was obtained as follows: $\mathrm{EL}$ $(\%)=\left(\mathrm{EC}_{1} / \mathrm{EC}_{2}\right) \times 100$.

\section{TNC Determination}

Total non structural carbohydrates (TNC) were analyzed based on the anthrone method described by Allen et al. (1974). Shoot and root samples were hydrolyzed enzymatically with $\alpha$-amylase and $0.5 \mathrm{ml}$ of sample extract were added to $5 \mathrm{ml}$ assay media containing $13.3 \mathrm{M} \mathrm{H}_{2} \mathrm{SO}_{4}$, $26.3 \mathrm{mM}$ thiourea and $10.3 \mathrm{mM}$ anthrone. The mixture was heated at $100{ }^{\circ} \mathrm{C}$ for $10 \mathrm{~min}$ and absorbance was read spectrophotometrically at $620 \mathrm{~nm}$. TNC concentrations were determined using a calibration curve done with $\mathrm{D}$ glucose as standards. The total amount of carbohydrate pools (pool $=$ TNC conc.$\times$ dry mass of plant part analyzed) in shoots and roots were also calculated as this may be important in assessing regrowth potential of plants (Santos and Trilica, 1978).

\section{Statistical Analysis}

Results were examined by one-way analysis of variance (ANOVA) using the SAS software (SAS Institute Inc.,1989). Treatment means were compared by Fisher's least significant differences (LSD) procedure at $P=0.05$. Qualitative data of aesthetic evaluation were analyzed using Kruskal-Wallis test.

\section{Results}

\section{Growth and Allocation}

Shoot and root dry biomass (DM) differed significantly $(P<0.01)$ between two species indicating the inherent variation in plant size (Fig. $1 \mathrm{~A}$ and $\mathrm{B}$ ). By the end of the drought period (day 40), shoot DM of Bermuda grass (BMD) was significantly reduced by $32 \%$, whereas the reduction was $15 \%$ in Bahia grass (BHI). However, root dry biomass did not differ significantly in both species owing to drought. 
Twenty-day terminal drought reduced the proportion of biomass allocated to shoots (reduced SMR) but increased the proportion allocated to roots (increased RMR) in both species (Fig. 2). At the end of the stress period, SMR of droughted plants decreased by $13.6 \%$ and $7.2 \%$ in BMD and BHI respectively in comparison to their controls. RMR of drought-stressed plants was $22 \%$ higher than that of control plants in BMD and it was $8.6 \%$ in BHI.

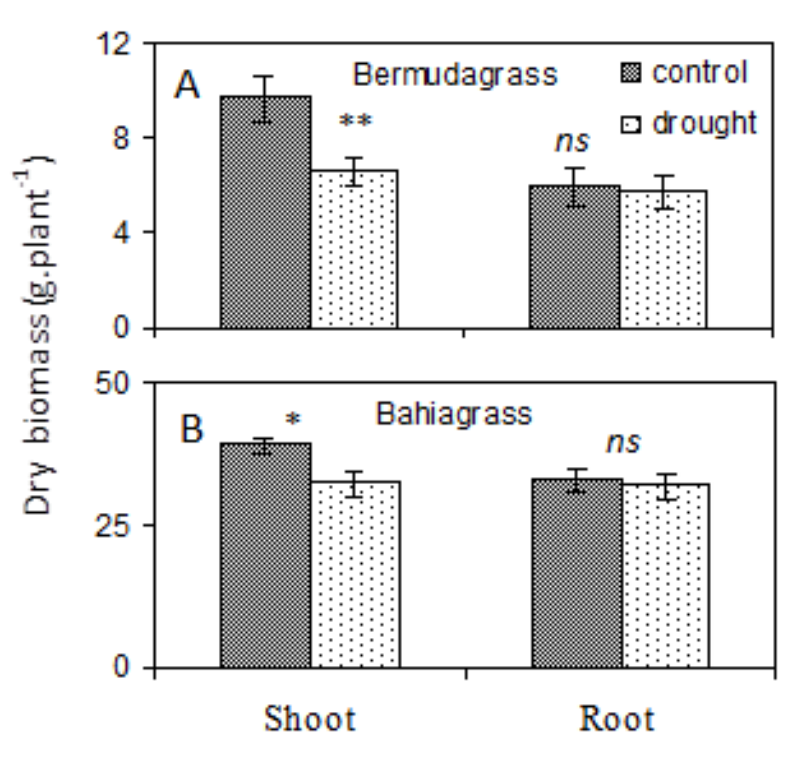

Fig. 1: Shoot and root dry biomass of Bermuda grass (A) and Bahia grass (B) after a 20 day drought. Vertical bars represent $\mathrm{SE}(\mathrm{n}=5)$. Significance is indicated as: $*_{-} P=0.05$, ** - $P=0.01$, ns - non significant.
During drought period, mean $\mathrm{RGR}_{\text {whole plant }}$ of stressed plants was lower $(P<0.05)$ than that of controls in both species. However, RGR root of control and stressed plants did not differ in BHI and BMD (Table 1). Though RGR shoot was higher in stressed plants of both BMD and BHI (1.5 fold and 6 fold respectively) after re-watering, a 3 fold reduction in $\mathrm{RGR}_{\text {root }}$ was resulted in stressed BMD plants compared to controls, while it was a 1.5 fold reduction in BHI. Nevertheless, $\mathrm{RGR}_{\text {whole plant }}$ of BMD was lower in droughted than in control plants during re-growth, and in BHI it was not different.

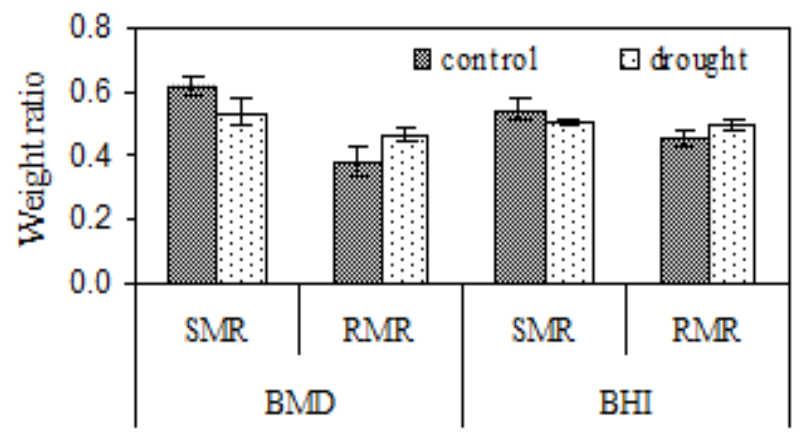

Fig. 2: Shoot mass ratio (SMR) and root mass ratio (RMR) of Bermuda grass (BMD) and bahia grass (BHI) as influenced by 20 day drought. Vertical bars represent SE $(\mathrm{n}=5)$. Significance is indicated as: *$P=0.05$,

Table 1: Relative growth rates of Bermuda grass (BMD) and Bahia grass (BHI) during drought and during recovery. Data are the means of five replicates.

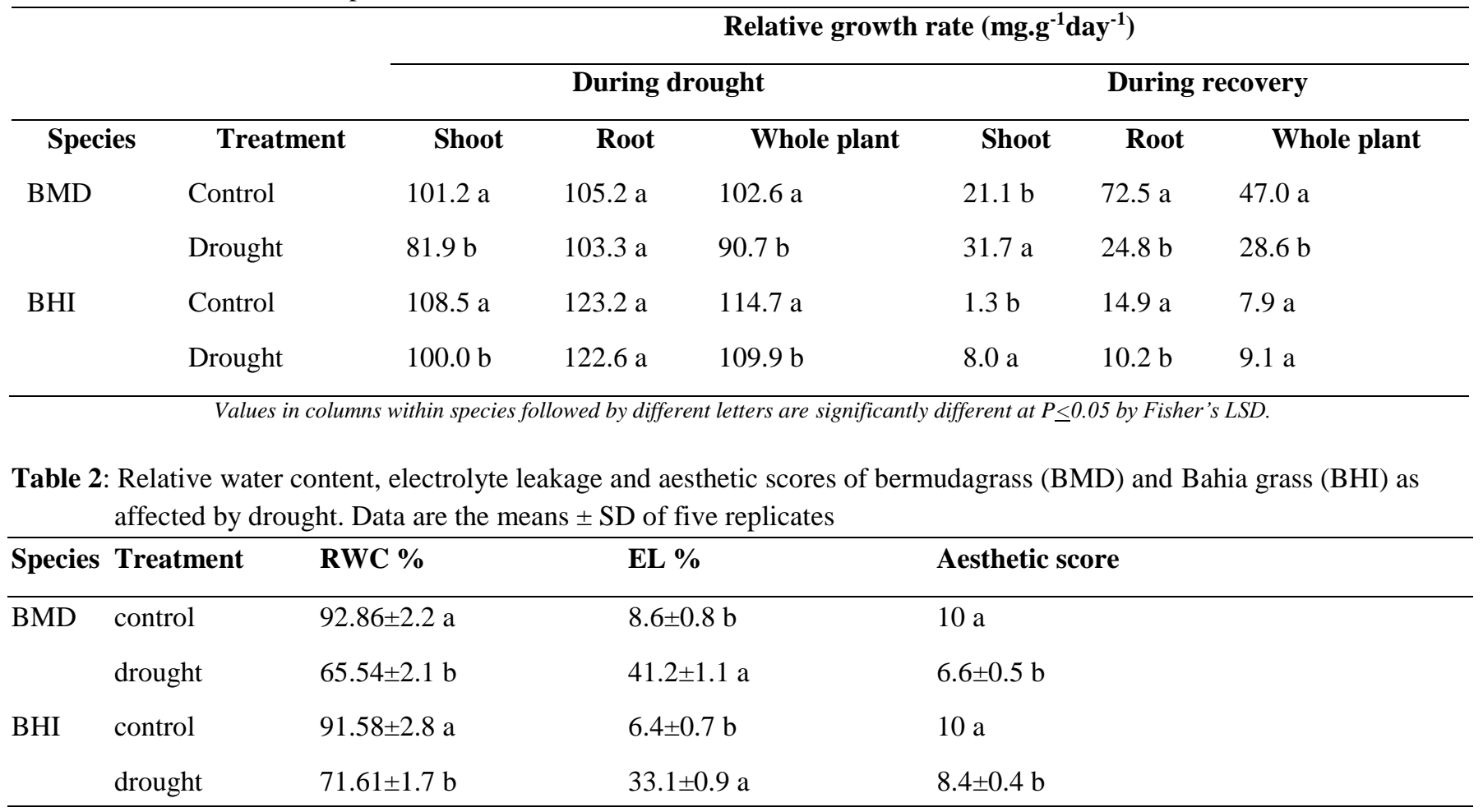

Values in columns within species followed by different letters are significantly different at $P \leq 0.05$ by Fisher's LSD. 


\section{TNC Concentrations and Pools}

TNC concentrations of shoots were significantly $(P<0.05)$ higher in drought-stressed plants than controls in both species (Fig. 3A). Drought induced TNC accumulation in BHI shoots was 2.7 fold greater than that of BMD. However, drought increased the shoot TNC concentration in BMD (48.1 mg/g) but decreased in BHI $(30 \mathrm{mg} / \mathrm{g})$ compared to their controls.

TNC pools in shoots differed significantly $(P<0.01)$ for both species between treatments (Fig. 3B). BHI showed a marked increase in shoot TNC pools owing to drought. Root TNC pool sizes had a similar pattern of change as in root TNC concentrations, but with different magnitudes. However, root pool size of stressed BHI was 3.5 fold higher than that of BMD.

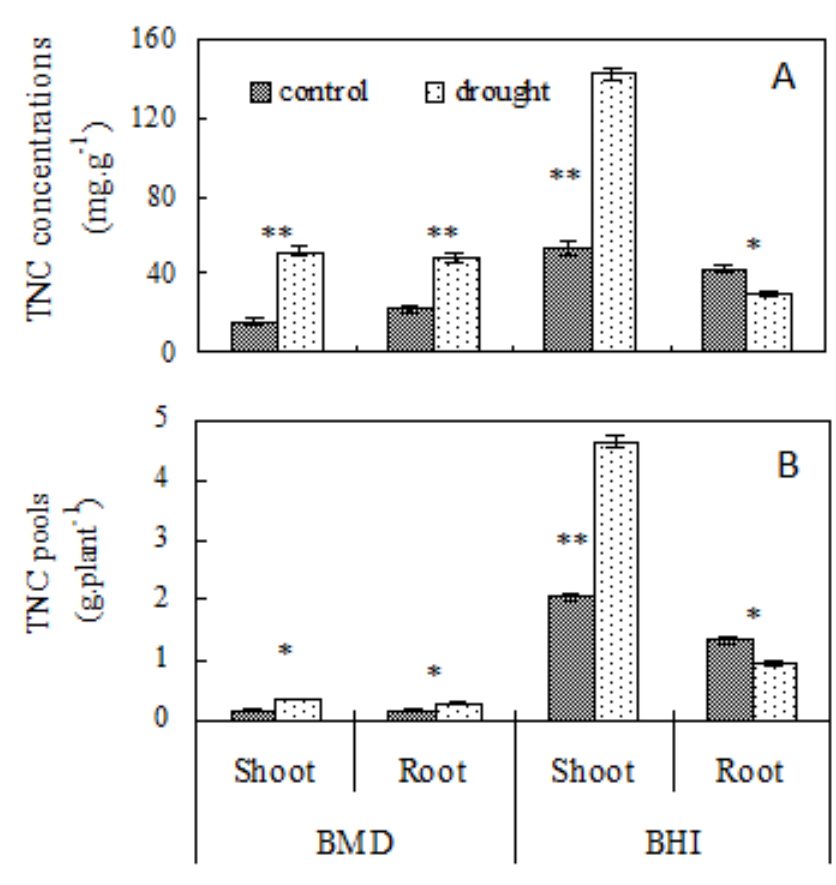

Fig. 3: (A) TNC concentrations and (B) TNC pools of Bermuda grass (BMD) and Bahia grass (BHI) as affected by a 20 day drought. Vertical bars represent $\mathrm{SE}(\mathrm{n}=5)$. Significance is indicated as: $*_{-} P=0.05$, ** $-P=0.01$.

\section{Plant Quality and Tissue Injury}

Under drought conditions, quality of both grasses decreased markedly (Table 2). Between 2 stressed species, BHI recorded the highest aesthetic score (8.4). Compared with the control plants, shoot RWC decreased only by $20 \%$ in BHI after 20 day drought-stress, whereas it was decreased approximately by $30 \%$ in BMD. Both species showed a 5fold increase in EL \% as affected by drought.

\section{Discussion}

Enhanced root growth during drought stress has been considered an important adaptation mechanism in many grasses (e.g. Molyneux and Davis, 1983; Huang and Fu,
2000). However our results are contradictory to the above notion. In the present study, drought did not have any impact on absolute change in root biomass in both species. Similar results have been reported by Loreti and Oesterheld (1996) with Paspalum dilatatum. Results from this study corroborate earlier findings (Huang and Gao, 2000) in that, high biomass fraction was partitioned in to roots during drought. Comparable results were reported by Fernandez et al. (2002) with Eragrostis lehmanniana and Bouteloue eripoda, both $\mathrm{C}_{4}$ grasses. However, the increase in allocation to roots in this study was mainly due to the absolute reduction in shoot biomass.

It was well established that, during drought stress, growth is ceased before photosynthesis (i.e. growth is more sensitive) and this leads to a surfeit of carbohydrates (Bressan, 2002). Our results with Bermuda grass are in accordance with this notion. Increase in shoot TNC concentrations and pools in both grasses in this study was comparable to the results reported previously (Busso et al., 1990: Huang and Gao, 2000: Chatterton et al., 1986). However, in present study, reduction in root TNC concentrations and pools in bahia grass was observed. This substantiates the records found in White (1973). A clear relationship was not observed between TNC levels and regrowth of both species. This may be due to the fact that, in addition to TNC concentrations or pools, many other factors affect regrowth, meristem availability and activity per se (Olsen and Richard, 1988).

Electrolyte leakage from drought stressed tissues can be used as a determinant of drought tolerance (Martin et al., 1987). Present study shows drought induced leakage of solutes in both species. Bahia grass was comparatively tolerant to drought than Bermuda grass in this aspect. Higher RWC and aesthetic scores also suggest a lesser impact of drought on bahia grass than Bermuda grass. EL, RWC and aesthetic scores were correlated to each other in both species (correlation coefficients: EL,RWC $=-0.94$, RWC, aestheics $=0.89$, EL, aesthetics $=-0.86$ ).

Accumulated carbohydrates during a stress are of importance to plants in three ways: to use in the regrowth, to make new structural components and for osmotic adjustment (White, 1973). In our study, accumulated carbohydrates in bermuda grass roots must have been spent mainly for recovery whereas, osmotic adjustment might be the priority in Bahia grass.

In summary, both grass species exhibited reduced performances (except root biomass) in response to drought. Bahia grass was better able to maintain its quality during drought than bermudagrass, thus can be recommended for low-maintenance landscaping efforts.

\section{References}

Allen SE (ed) (1974) Chemical analysis of ecological materials Section v: Organic constituents Blackwell Oxford pp 245 247 
Barrs HD and Weatherley PE (1962) A re-examination of the relative turgidity technique for estimating water deficits in leaves. Aust $J$ Biol Sci 15: 413-428. DOI: $\underline{10.1071 / \mathrm{BI} 9620413}$

Bressan RA (2002) Stress physiology In: Taiz, L and Zeiger, E (eds) Plant Physiology Third edition Sinauer Associates, Inc, USA pp 591-602.

Busso CA, Richards JH and Chatterton NJ (1990) Nonstructural carbohydrates and spring regrowth of two cool-season grasses: Interaction of drought and clipping. Journal of Range management 43(4): 336-343. DOI: $\underline{10.2307 / 3898928}$

Chatterton NJ, Harrison PA and Bennett JH (1986) Environmental effects on sucrose and fructan concentrations in leaves of Agropyron spp In: J Cronshaw, WJ Lucas and RT Giaquinta (eds), Phloem transport Alan R Liss, Inc, New York pp 471-476.

Deregibus VA, Trlica MJ and DA Jameson (1982) Organic reserves in herbage plants: their relationship to grassland management In:M Rechigi, Jr, (ed) CRC Handbook of Agricultural Productivity Vol I Plant Productivity CRC Press Inc, Boca Raton, Flor pp 315-344.

Fernandez RJ, Wang M and Reynolds JF (2002) Do morphological changes mediate plant responses to water stress? A steady state experiment with $\mathrm{C}_{4}$ grasses. New Phytologist 155: 7988. DOI: $10.1046 /$ j.1469-8137.2002.00438.x

Galiano EF (1985) The small-scale pattern of Cynodon dactylon in Mediterranean pastures. Vegetatio 63: 121- 127. DOI: $\underline{10.1007 / \mathrm{BF} 00044062}$

Huang B and Fu J (2000) Photosynthesis, respiration and carbon allocation of two cool-season perennial grasses in response to surface soil drying. Plant and Soil 227: 17-26. DOI: $\underline{\text { 10.1023/A:1026512212113 }}$

Huang B and Gao H (2000) Root physiological characteristics associated with drought resistance in tall fescue cultivars. Crop Sci 40: 196-203. DOI: $\underline{10.2135 / \text { cropsci2000.401196x }}$
Hunt R (1982) Plant growth curves: the functional approach to growth analysis London, UK: Edward Arnold

King JR, Scott JM and Boschma SP (1997) Forage persistence under extremes of cold and drought XVII International Grassland Congress 1997, Canada pp 403-410

Loreti J and Oesterheld M (1996) Interspecific variation in the resistance to flooding and drought in populations of Paspalum dilatatum from different topographic positions. Oecologia 108: 279-284. DOI: 10.1007/BF00334652

Martin V, Pallardy SG and Bahari ZA (1987) Dehydration tolerance of leaf tissue of six woody angiosperm species. Physiol Plant 669: 182-186. DOI: 10.1111/j.13993054.1987.tb01964.x

Molyneux DE and Davis WJ (1983) Rooting pattern and water relations of three pasture grasses growing in drying soil. Oecologia 58: 220-224. DOI: $\underline{10.1007 / \mathrm{BF} 00399220}$

Nayyar H and Chander S (2004) Protective effects of polyamines against oxidative stress induced by water and cold stress in chickpea. J Agronomy \& Crop Science 190: 355-365. DOI: $\underline{10.1111 / \mathrm{j} .1439-037 X .2004 .00106 . \mathrm{x}}$

Olson BE and Richards JH (1988) Tussock regrowth after grazing: Intercalary meristem and axillary bud activity of tillers of Agropyron desertorum. Oikos 51: 374-382. DOI: $\underline{10.2307 / 3565321}$

Santos GL and Trilica MJ (1978) Clipping effects on production and carbohydrate reserves of blue gramma and wetern wheatgrass pp 384-386 In: $1^{\text {st }}$ Int Range congr, Denvor, Colorado.

SAS Institute Inc (1989) SAS/STAT User's Guide Release 603 Ed SAS Institute Inc, Cary, NC

Tischler CR and Burson BL (1995) Evaluating different bahiagrass cytotypes for heat tolerance and leaf epiculticular was content. Euphytica 84: 229-235. DOI: $\underline{10.1007 / \mathrm{BF} 01681815}$

White LM (1973) Carbohydrate reserves of grasses: A review. Journal of Range management 26(1): 13-18. DOI: $\underline{10.2307 / 3896873}$ 